


\title{
NOVOS PERCURSOS E ATORES EM SÃO PAULO: INDICATIVOS PARA UMA AGENDA DE PESQUISA
}

\author{
SÃO PAULO: NOVOS PERCURSOS E ATORES - SOCIEDADE, CULTURA E POLÍTICA, \\ de Kowarick, Lúcio e Marques, Eduardo (orgs.). São Paulo: Editora 34/Centro de Estudos da Metrópole, 2011.
}

JEFFERSON O. GOULART

[1] Moya, Maria Encarnación. "Os estudos sobre a cidade:quarenta anos de mudança nos olhares sobre a cidade e o social". In: Kowarick, Lúcio e Marques, Eduardo (orgs.). São Paulo: novos percursos e atores - sociedade, cultura e politica. São Paulo: Editora 34/Centro de Estudos da Metrópole, 2011, pp. 25-50.

[2] A esse respeito, ver: Kowarick, Lúcio. A espoliação urbana. $2^{\mathrm{a}}$ ed. Rio de Janeiro: Paz e Terra, 1993.
É conhecido o enigma da esfinge: decifra-me ou te devoro. A ideia fundamental consiste em que o ignoradoé capaz de nos tragar precisamente pela dificuldade de compreendê-lo. Provavelmente a mais radical efetivação do enunciado tenha se materializado por ocasião da ruptura com o Ancien Régime e na invenção da modernidade, quando Saturno revelou sua fúria e devorou os próprios filhos — os rebentos da revolução. A pergunta indigesta permanece: mesmo em um novo mundo pautado pela razão, estaríamos condenados à ignorância?

Particularmente no que respeita aos estudos urbanos, nossa trajetória intelectual é valiosíssima. As pesquisas de diferentes áreas do conhecimento e mesmo aquelas de abordagem interdisciplinar produziram um extenso mosaico sobre a realidade urbana brasileira, notadamente das grandes cidades. Não por acaso, a obra organizada por Kowarick e Marques se inicia no olhar panorâmico e retrospectivo sobre essa produção.

O legado desse conhecimento influenciou gerações de estudos, demarcando a indissociável relação entre segregação socioespacial e dinâmica capitalista, ou seja, o urbano tratado como objeto privilegiado de reprodução do capital sob o impulso do Estado mediante a existência de um exército industrial de reserva. Pobreza e desigualdade tematizaram a literatura correspondente para depois se fragmentarem teórica e metodologicamente. ${ }^{1}$

Mesmo assumindo-a como uma escolha arbitrária, a síntese dessa tradição de pesquisa pode ser identificada no achado seminal de que a percepção de caos e a aparente ausência de ordem tinham, sim, uma lógica: a da espoliação urbana. ${ }^{2}$ Mais ainda: a acumulação foi operada por meio de mecanismos de dilapidação da força de trabalho (e nas formas perversas de sua reprodução), da primazia do capital financeiro-imobiliário que se manifestou em grandes ações das incorporado- 
ras e da interrupção de direitos de cidadania mediante uma ação estatal autoritária. Enfim, uma urbanização anômicaª que se traduziu em uma desordem ordenada.

A multiplicidade de influências teóricas e de escolhas metodológicas dessa rica tradição - dentre as quais se destaca o prestígio da matriz estruturalista da sociologia marxista francesa - ensejou um consenso genérico sobre o processo de urbanização em geral e particularmente sobre sua maior cidade: "cidade multifacetada, plena de contrastes, conjugando dinamismo, coração econômico do país marcado por vastas extensões de pobreza". ${ }^{4}$ São Paulo é isso e muito mais.

São Paulo:novos percursos e atores se debruça precisamente sobre esse "muito mais", e oferece um largo panorama das mudanças recentes, das permanências e das rupturas que fizeram dessa megalópole um lugar paradoxal que provoca amor e ódio, e cujo magnetismo já não é mais o mesmo a ponto de atrair e fascinar os incautos. Assim desmistificam-se as previsões demográficas do século XX ${ }^{5}$, constatação inseparável da tendência à sobreposição de funções de estruturas econômicas industriais e terciárias. ${ }^{6}$ Mais ainda: as desigualdades do mercado de trabalho têm determinações anteriores ao acesso à ocupação, relacionadas aos atributos desses candidatos ao emprego e aos contextos nos quais estão inseridos.7

Achave do enigma foi anunciada no título da obra, na adoção de um adjetivo temporal no plural: novos. É em torno dessa escolha (menos semântica e mais conceitual e analítica) e de sua subjacente aspiração ao postulado de que, com efeito, emergiram novos personagens e engrenagens, que o livro deve ser compreendido. E a referência cronológica não deve ser ignorada: embora nem todos os autores a adotem como recorte específico, as últimas quadro décadas alteraram substantivamente as configurações socioeconômica e político-institucional da cidade. Dessa perspectiva, organizadores e autores não só são convincentes como remetem a problemas cuja complexidade ainda precisa ser analisada contínua e detidamente.

Nesses termos, São Paulo:novos percursos e atores ingressa na galeria das leituras obrigatórias sobre o urbano porque sintetiza uma guinada sutil nos estudos sobre a grande megalópole. E as razões dessa distinção são diversas.

Primeiro, naturalmente, porque é convincente na pretensão de demonstrar a originalidade de alguns desses novos atores e percursos. Vista de um ângulo genérico ou aparente, evidente que São Paulo permanece segregadora, desigual e paradoxal: opulência e riqueza de um lado, vulnerabilidade e miséria de outro. Mas o tempo e os subterrâneos da cidade abrigaram mudanças importantes de quantidade e qualidade que a tornaram efetivamente diferente sob vários aspectos, a
[3] Kowarick e Marques (orgs.), op. cit., p. 15 .

[4] Ibidem, p. 9.

[5] Baeninger, Rosana. "Crescimento da população na Região Metropolitana de São Paulo: descontruindo mitos do século XX". In: Kowarick, Lúcio e Marques, Eduardo (orgs.), op. cit., pp. 53-78.

[6] Comin, Alvaro. "Cidades-regiões ou hiperconcentração do desenvolvimento? O debate visto do Sul". In: Kowarick, Lúcio e Marques, Eduardo (orgs.), op. cit., pp.157-177.

[7] Guimarães, Nadya; Brito, $\mathrm{Mu}$ rillo de; Silva, Paulo Henrique da. "Os mecanismos de acesso (desigual) ao trabalho em perspectiva comparada". In: Kowarick, Lúcio e Marques, Eduardo (orgs.), op. cit., pp. 179-204. 
[8] Caldeira, Teresa Pires do Rio. “O rap e a cidade: reconfigurando a desigualdade em São Paulo". In: Kowarick, Lúcio e Marques, Eduardo (orgs.), op.cit., p.318.

[9] Telles, Vera da Silva; Hirata, Daniel. "Cidade e práticas urbanas: nas fronteiras incertas entre o ilegal, o informal e o ilícito". In: Kowarick, Lúcio e Marques, Eduardo (orgs.), op. cit., p.391.

[10] Miraglia, Paula. "Homicídios: guias para a interpretação da violência na cidade". In: Kowarick, Lúcio e Marques, Eduardo (orgs.), op. cit., p. 334 .

[11] Leme, Maria Cristina da Silva; Feldman, Sarah. "A presença estrangeira: processos urbanos e escalas de atuação". In: Kowarick, Lúcio e Marques, Eduardo (orgs.), op. cit., pp. 131-154.

[12] Saraiva,Camila;Marques,Eduardo. "Favelas e periferias nos anos 2000". In: Kowarick, Lúcio e Marques, Eduardo (orgs.), op.cit.,p.119.

[13] Ibidem, pp.126-7.

[14] Tatagiba, Luciana. "Relação entre movimentos sociais e instituições políticas na cidade de São Paulo: o caso do movimento de moradia". In: Kowarick, Lúcio e Marques, Eduardo (orgs.), op. cit., pp. 233-252. ponto de a oposição centro-periferia não ser mais suficiente como modelo explicativo das desigualdades urbanas.

Alguns exemplos simbolizam bem essas mudanças. O primeiro deles reside no plano da identidade cultural e particularmente na emergência do rap como expressão periférica de ressignificação da vida pública fundada em uma "ordem moralista, onde não existe lugar para diferença". ${ }^{8}$ Outro é a dificuldade de discernir linhas divisórias precisas entre o "correto" e o "ilegal, o informal e o ilícito", afinal essas dimensões (como o negócio do comércio de drogas) são socialmente legitimadas, assim como "nesses pontos de fricção que homens e mulheres negociam a vida e os sentidos da vida. No fio da navalha. $O$ fato é que os indivíduos e suas famílias transitam nessas tênues fronteiras do legal e do ilegal...".9

Além da presença de novos atores (caso emblemático do PCC), "o mapa da violência em São Paulo revela o confinamento da violência letal nas periferias: as franjas da cidade concentram o maior numero de homicídios". ${ }^{10}$

Antes cidade de portugueses, italianos, espanhóis, orientais, sírio-libaneses, ex-escravos e judeus que imprimiram suas marcas a bairros, costumes e à materialidade da urbe, a São Paulo contemporânea acolhe novos estrangeiros, cujo ingresso é útil para também compreender processos complementares como a produção de serviços urbanos, as relações capital-trabalho ou as interações culturais. ${ }^{11}$

Cidade de favelização tardia comparativamente ao Rio de Janeiro, São Paulo vem registrando uma expansão desse tipo de habitação precária que sintetiza um fenômeno indissociável de sua dinâmica econômica, com destaque para a precarização do trabalho como sintoma de um estado de vulnerabilidade social mais amplo. Essa trajetória, contudo, não é linear. Tal heterogeneidade autoriza a formulação de uma "tipologia das favelas", cuja "análise comparativa permite sustentar a existência de uma razoável variabilidade entre núcleos favelados da cidade". ${ }^{12}$ Ainda mais surpreendente (e perturbador) é que "em termos relativos, as favelas não apenas melhoraram, como se aproximaram da situação de outros moradores da cidade, sugerindo um processo de convergência, incompleto e talvez excessivamente lento, mas mesmo assim existente entre os indicadores médios de favelados e não favelados". ${ }^{13}$

Outros exemplos se situam no plano das relações políticas. De um lado, há que se reconhecer o processo de institucionalização da participação, mas essa trajetória não prescindiu da permanência dos movimentos sociais. Pelo contrário, estes ainda são vigorosos, sobretudo, nas temáticas mais sensíveis das políticas públicas, caso notável da centralidade da habitação. ${ }^{14}$ Claro que as práticas de clientela não desapareceram, mas os atores também não são apenas os tradicionais, 
aos quais se juntaram as articuladoras do associativismo, "novo tipo de ator criado na última década [que] ganhou centralidade e posicionou-se ao lado dos movimentos pela sua capacidade de agregação de demandas e de coordenação da atuação de outros atores". ${ }^{15}$

Nessa senda, a violência organizada não se confunde com os movimentos sociais, mas não deixa de exprimir um novo e importante protagonista na cena urbana. Se em tempos não tão remotos a ascensão socioeconômica transcorria por meio das teias de integração social do trabalho, agora o cenário é bem diferente, pois "abriu-se espaço para que o 'mundo do crime' disputasse legitimidade com toda essa série de instituições e atores tradicionalmente legítimos nas periferias da cidade".${ }^{16}$ Tais mudanças foram percebidas inclusive pelo cinema, que as retratou de maneira ora caricata, ora mais realista, através de registros que às vezes selam o abismo entre distintos universos sociais e a impossibilidade de convívio entre esses mundos diferentes ou que exaltam marcas identitárias da periferia. ${ }^{17}$

No plano estritamente político, a análise de Limongi e Mesquita ${ }^{18}$ demonstra a polarização entre direita e esquerda no comportamento do eleitorado paulistano desde o restabelecimento das eleições diretas para prefeito da capital, em 1985. Os autores observam a estabilidade do eleitorado e enfatizam que as disputas têm nos eleitores de educação média (no quesito socioeconômico) e de centro (no quesito ideológico) seu núcleo decisivo. Se tais postulados estiverem corretos - e há fortes razões para aceitá-los - , os resultados de 2012 marcam uma importante guinada rumo à esquerda, cuja inclinação do centro ainda está por ser analisada.

Mas há pelo menos duas omissões importantes nas abordagens políticas do livro.A primeira diz respeito não às estratégias eleitorais e ao comportamento (relativamente flutuante) do eleitorado, mas ao desempenho desses diferentes governos de direita e de esquerda, ou seja, como estes têm se comportado na gestão de políticas públicas e quais teriam sido as razões para as oscilações do eleitorado centrista.

Outra ausência é a escassez de análises de gestão urbana, isto é, as políticas públicas e os instrumentos através dos quais os diferentes governos municipais têm enfrentado a agenda urbana: a gestão do território, a aplicação da função social da propriedade, o tratamento das agudas questões da mobilidade urbana e da habitação social (dentre outras), enfim uma avaliação político-institucional do modelo de produção do espaço urbano. Nesse sentido, um balanço - mesmo que preliminar - sobre a aplicação do Estatuto da Cidade seria indispensável, afinal, trata-se de bandeira histórica do movimento pela reforma urbana que vigora desde 2001, regulamentou o capítulo da Política Urbana da Constituição cidadã e que tem suas marcas institucionais no Plano Diretor Estratégico de São Paulo.
[15] Lavalle, Adrian Gurza; Castello, Graziela; Bichir, Renata. "Movimentos sociais e articuladoras no associativismo do século XXI". In: Kowarick, Lúcio e Marques, Eduardo (orgs.), op. cit., p. 260.

[16] Feltran, Gabriel. “Transformações sociais e políticas nas periferias de São Paulo". In: Kowarick, Lúcio e Marques, Eduardo (orgs.), op. cit., p. 361.

[17] Hamburguer, Esther; Stücker, Ananda; Carvalho, Laura; Ramos, Miguel. "Cinema contemporâneo e políticas de representação da e na urbe paulistana". In: Kowarick, Lúcio e Marques, Eduardo (orgs.), op. cit., pp. 279-299.

[18] Limongi, Fernando; Mesquita, Lara. "Estratégia partidária e clivagens eleitorais: as eleições municipais pós-redemocratização". In: Kowarick, Lúcio e Marques, Eduardo (orgs.), op. cit., pp. 207-232. 
[19] Kowaricke Marques, op.cit.,p.16.

[20] Kowarick, Lúcio. "O centro e seus cortiços: dinâmicas socioeconômicas, pobreza e política". In: Kowarick, Lúcio e Marques, Eduardo (orgs.), op.cit., p.88.
A segunda razão do caráter original do livro diz respeito à sua pluralidade teórica e metodológica, mérito que corrobora a correção de abordagens interdisciplinares e multidisciplinares sobre um mesmo objeto.

Definitivamente não há hierarquia entre escolhas de ferramentas sociológicas, urbanísticas, etnográficas, demográficas, políticas, comunicacionais e quaisquer outras. Pelo contrário, seus usos simultâneos produzem modelos explicativos mais sólidos e análises mais críveis. Essa diversidade de olhares revela descobertas e resultados complementares. Tal virtude contrasta com a tendência tão em voga de fragmentação excessiva do conhecimento, inclinação absorvida pelas instituições científicas e respectivas agências cujo maior risco é o confinamento do saber. São Paulo: novos percursos e atores ousa ir contra a maré, e o faz de forma persuasiva.

A terceira virtude da obra é que, mesmo não tendo a pretensão de ser conclusiva, remete a uma agenda de pesquisa que, embora já se manifestasse de forma mais ou menos difusa, ainda não fora objeto de um esforço de sistematização.

Em boa medida, essa agenda está anunciada nos temas e nas abordagens dos autores - e até poderíamos aceitar o agrupamento apresentado pelos organizadores: "viver e habitar na cidade"; "trabalho e produção"; "política e representação"; e "sociabilidade, cotidiano e violência" - , mas a proposta ainda se revela incompleta. E este é um ponto delicado, pois também envolveescolhas éticas ealguns tabus no universo acadêmico.

Um exemplo provocativo: conhecemos razoavelmente a precariedade da infraestrutura urbana das periferias, das favelas e dos cortiços, estudamos as diferentes expressões da violência e suas determinações e impactos ou ainda sabemos dimensionar minimamente os efeitos da informalidade nas relações de trabalho, todas essas dimensões relativas aos pobres e miseráveis, mas são escassos os estudos sobre os "de cima" da pirâmide social, como se sua posição socioeconômica privilegiada fosse justificativa moral para ignorá-los.

Essa lacuna é reconhecida pelos próprios organizadores quando advertem que [o livro] "não analisa centralmente um outro lado da cidade, que envolve parcela significativa da riqueza nacional". ${ }^{19}$

A propensão a dar as costas a esses atores gera prejuízos cognitivos à medida que desconhecemos como vivem, como se organizam e como atuam tais personagens. Ou seja, como suas escolhas (e percursos) interferem na dinâmica urbana. Claro que a "desumanidade da Cracolândia"2o, por exemplo, é um grande tema de pesquisa, porém,é inegável que a solução dessa chaga - em suas múltiplas dimensões: da marginalização social per se, da generalização do consumo de drogas, da saúde pública ou da violência — implica conhecer o "outro 
lado", qual seja, a banda dos concertos da Sala São Paulo e os interesses imobiliários que operam no Projeto Nova Luz (e que são característicos de quaisquer processos de gentrification). Ou ainda: que o conhecimento sobre a expansão da favelização é inseparável da ação dos interesses do capital imobiliário e da conduta empresarial nas relações trabalhistas. Assim sucessivamente poderiam ser invocados exemplos ad nauseam. Fato é que ainda conhecemos pouco os "de cima", e como estes efetivamente interferem na cena urbana e nas decisões públicas.

Em seu primeiro pronunciamento após vencer as eleições de 2012, o novo prefeito de São Paulo, Fernando Haddad, declarou que a cidade foi inventada para proteger e promover a integração social, e que era seu compromisso resgatar tais ideais. Bom presságio, em que pese o sabido abismo que separa o discurso normativo da realidade. O enigma da esfinge permanece nos desafiando: ou compreendemos São Paulo ou ela nos devora. Nesses termos, seria mais do que oportuno - na verdade um imperativo - absorver a advertência de J. Jacobs de que cidades vivas têm em suas próprias crises os germes da regeneração. ${ }^{21} \mathrm{O}$ próximo período poderá responder se esse otimismo contido é justificável.

Novos personagens e seus respectivos caminhos foram enunciados em 16 textos por 26 autores — baliza paradigmática na agenda de pesquisa sobre o urbano em geral e São Paulo em particular - , restando agora continuar a decifrá-los. Esteé, simultaneamente, o mérito e o desafio de São Paulo:novos percursos e atores.

JefFERson O. Goulart é professor do Departamento de Ciências Humanas da Faculdade de Arquitetura, Artes e Comunicação da Universidade Estadual Paulista (Unesp) e pesquisador do Centro de Estudos de Cultura Contemporânea (Cedec).
[21] Jacobs, Jane. Morte e Vida de grandes cidades. São Paulo: Martins Fontes, 2000. 

ASSINE NOVOS

ESTUDOSE

menila a GeSSO

AOAGERVO DA REVISTA 
DESDE O INICIO DOS ANOS I980, NOVOS ESTUDOS TEM PUBLIGADO ARTIEOS, DEBATES, ENTREVISTAS, RESENHAS E DOSSIÊS QUE SE TORNARAM REFERÊNGCIA OBRIGATÓBIIA PARA DIVERSAS DISGIPLINAS NO ÂMBITO DAS ClÊNYCIAS SOCIAIS, DAS ARTES E DA LITERATURA. A EXEMPLO DAS PUBLICAÇÕES MAIS EXPRESSIVAS DO MEIO, A REVISTA DISPÕE AGORA DE SEU AGERVO EM FORMATO ELETRÔNICO. OS VOLUMES - MUTTOS DELES ESEOTADOS HÁ MAIS DE UMA DÉCADA - ENGONTRAM-SE FAGILMENTE AGESSIVEIS NO SIIE DO GEBRAP. PARA TER ACESSO A ESSE MATERHAL SEM EQUIVALENTE NOS ARQUIVOS DE PERIÓDICOS GIENTIFICOS BRASILEIROS, BASTA FAZER UMA ASSINATURA DA REVISTA. ASSINE NOVOS ESTUDOS. CUSTA POUCO ESTAR CONEGTADO COM A PRODUÇĨO MAIS SOFISTIGADA DAS HUMANIDADES NO BRASIL.

www.cebrap.org.br 
ESTE NÚMERO FOI FINANCIADO PELA FUNDAÇÃo CARLOS CHAGAS 